\title{
Inhibitory Effects of Saururus chinensis (LouR.) BaILL on the Development of Atopic Dermatitis-Like Skin Lesions in NC/Nga Mice
}

\author{
Myoung Suk ChoI ${ }^{a}$ Eui Chul Kim, ${ }^{a}$ Hyung Suk LeE, ${ }^{a}$ Sun Kwang Kim,${ }^{a, c}$ Hyun Myung Chor,${ }^{a}$ \\ Jung Hyuk PARK, ${ }^{a}$ Jae-Bok Han, ${ }^{a}$ Hyo Jin AN, ${ }^{b}$ Jae Young UM, ${ }^{b}$ Hyung Min KIM, ${ }^{b}$ Ah-Reum Han, ${ }^{c}$ \\ Moo Chang Hong,${ }^{c}$ Hyunsu BAE, ${ }^{c}$ and Byung-Il MiN $*, a, d$ \\ ${ }^{a}$ Department of East-West Medicine, Graduate School, Kyung Hee University; ${ }^{b}$ College of Oriental Medicine, Institute of \\ Oriental Medicine, Oriental Medical Science Center, Kyung Hee University; ${ }^{c}$ Department of Physiology, College of \\ Oriental Medicine, Kyung Hee University; and ${ }^{d}$ Department of Physiology, College of Medicine, Kyung Hee University; \\ \#1 Hoegi-dong, Dongdaemoon-gu, Seoul 130-701, Republic of Korea. \\ Received May 23, 2007; accepted October 16, 2007; published online November 5, 2007
}

The present study was performed to examine whether the leaves of Saururus chinensis (Lour.) BaILL (SC), an herb used for the management of various skin diseases including atopic dermatitis (AD) in Eastern countries, inhibited the development of AD-like skin lesions in NC/Nga mice which was induced by repeated application of picryl chloride ( $\mathrm{PiCl})$. The efficacy of $\mathrm{SC}$ was judged by measurement of skin severity, itching behavior, histological study, serum IgE levels, IL-4 and IFN- $\gamma$ in lymph nodes. Oral administration of SC extract to the PiCltreated NC/Nga mice for 8 weeks ( $5 \mathrm{~d}$ per week) inhibited significantly the development of AD-like skin lesions macroscopically. Histologically, SC inhibited dermatitis changes like hypertrophy, hyperkeratosis, and infiltration of inflammatory cells into epidermis and dermis. The itching behavior and serum IgE level decreased significantly after SC administration. SC administration enhanced IFN- $\gamma$ mRNA expression but did not have an effect on IL-4 mRNA expression. These results suggest that SC could inhibit the development of AD-like skin lesions in NC/Nga mice possibly through modulating the Th1/Th2 imbalance by the promoting of Th1 cell response. Thus, SC may be an alternative substance for the management of AD patients.

Key words atopic dermatitis; Saururus chinensis; NC/Nga mouse; interferon gamma; interleukin-4; Th1/Th2

Atopic dermatitis (AD) is a common inflammatory skin disorder that is both uncomfortable and distressing to patients as a result of its associated intense pruritus and unsightly lesions. When severe, AD can be extremely disabling, causing major psychological problems, and, in the case of a young child, be overwhelming to the entire family. ${ }^{1)} \mathrm{AD}$ is a genotypic diathesis in which minor skin stimulation is perceived as an itching that, when scratched or rubbed, elicits a heightened immune response. The heightened immune response leads to the development of eczema, which is the clinical syndrome of eczematous dermatitis group of inflammatory skin conditions characterized by pruritus, pale, erythematous and violaceous hues, vesiculation, erosion, scaling, exudation, crusting, lichenification, and excoriations. ${ }^{2)}$

Most patients with AD have peripheral blood eosinophilia and increased serum immunoglobulin (Ig) E concentrations for which the cytokines interleukin (IL)-4, IL-5 and IL-13 produced by T-helper (Th) 2 cells are responsible. ${ }^{3,4)}$ In contrast to increased Th2 and Th2 cytokine, most patients with AD have decreased Th1 cells and Th1 cytokines such as interferon gamma (IFN- $\gamma$ ) and IL-12, which are capable of counteracting Th2 responses. ${ }^{5-7)}$ It is well established that the Th1/Th2 imbalance skewed to Th2 plays important roles in the development of $\mathrm{AD} .^{8,9)}$ But, the pathogens of $\mathrm{AD}$ are not completely understood, although several cell types (e.g., $\mathrm{T}$ lymphocytes, Langerhans cells, eosinophils, keratinocytes) and factors (e.g., cytokines and immunoglobulins, particularly IgE) have been implicated. ${ }^{10)}$

It has been accepted that topical steroid therapy is crucial for the management of the disease, but it cannot be used for long periods and side effects were frequently observed. Re- sults from several studies indicate that AD patients may benefit from herbal therapy in Oriental medicine. ${ }^{11)}$ Saururus chinensis (LouR.) BAILL (SC) is a perennial herbaceous plant used in the treatment of various conditions, such as edema, jaundice, gonorrhea, as an antipyretic, diuretic, and anti-inflammatory agent in Korean folk medicine. ${ }^{12,13)}$ Moreover, $\mathrm{SC}$ is an herb used for the management of various skin diseases including AD in Eastern countries, especially in Korea, Japan and China. Only a few reports have documented the biological activities of SC herb indicating that the extract and lignans isolated exhibited hepato-protective, anti-inflammatory or antioxidative activity. ${ }^{14-17)} \mathrm{SC}$ contains flavonoids, including quercetin, quercitrin, isoquercitrin and rutin, as active components. It has been reported that flavonoids possess a number of biological effects such as antiallergic, anti-inflammatory, antiviral, antiproliferative and anticarcinogenic activities. ${ }^{18,19)}$ Antiinflammatory effect of these flavonoids suggests the possibility of their therapeutic efficacy in various inflammatory diseases. ${ }^{20)}$ However, it has not yet been studied if and how SC suppresses the development of AD. In this study we investigated therapeutic effects of SC on ADlike skin lesions in NC/Nga mice.

The NC/Nga mouse is the most extensively studied animal model of AD. ${ }^{21,22)}$ The NC/Nga strain originated from Japanese fancy mice and was established as an inbred strain by Kondo et al. in $1957 .{ }^{23)} \mathrm{NC} / \mathrm{Nga}$ mice have been reported to develop AD-like eczematous skin lesions when kept in an air-uncontrolled conventional room but not when maintained under specific pathogen-free (SPF) conditions. ${ }^{21,22)}$ Recently, it has also been shown that NC/Nga mice develop AD-like skin lesions after repeated application of hapten under SPF 
conditions. $^{24,25)}$ In this study we used the hapten-induced dermatitis model since repeated hapten (picryl chloride, $\mathrm{PiCl}$ ) treatment causes apparent dermatitis in $100 \%$ of $\mathrm{NC} / \mathrm{Nga}$ mice. ${ }^{22,24-26)}$ In the present study, we measured skin severity, histological study, itching behavior, serum IgE level, IFN- $\gamma$ and IL-4 levels in lymph nodes to examine inhibitory effects of SC on the development of AD-like skin lesions in $\mathrm{NC} / \mathrm{Nga}$ mice.

\section{MATERIALS AND METHODS}

Animals Female 4-week-old NC/Nga mice were purchased from SLC (Shizuoka, Japan) and were maintained for 2 weeks before the start of the experiments. They were housed in an air-conditioned animal room with a 12-h light/dark cycle (08:00 — 20:00 h light, 20:00—08:00 h dark), at $23 \pm 2{ }^{\circ} \mathrm{C}$ and a humidity of $50 \pm 10 \%$. The study was approved by the Institutional Animal Care and Use Committee of Kyung Hee University and all procedures were conducted in accordance with the U.S. National Institutes of Health guidelines. Mice were divided into three groups: (1) control group $(0.9 \%$ normal saline administered $\mathrm{NC} / \mathrm{Nga}$ mice, $0.2 \mathrm{cc} / \mathrm{d}, n=7)$, (2) SC100 group (100 mg/kg SC extract administered NC/Nga mice, $0.2 \mathrm{cc} / \mathrm{d}, n=8$ ), (3) SC250 group $(250 \mathrm{mg} / \mathrm{kg}$ SC extract administered NC/Nga mice, $0.2 \mathrm{cc} / \mathrm{d}$, $n=8)$.

Reagents 1-Chloro-2,4,6-trinitrobenzene (Picryl Chloride, purchased by Tocris Japan) was used after recrystallization with ethanol. Picryl chloride $(\mathrm{PiCl})$-induced AD-like skin lesion was developed in $\mathrm{NC} / \mathrm{Nga}$ mice according to standard instructions provided by Charls River Japan. Briefly, the abdomen and ears of mice were sensitized epicutaneously with $150 \mu \mathrm{l}$ of $5 \% \mathrm{PiCl}$ dissolved in an ethanol and acetone mixture $(4: 1)$. On day 5 after sensitization, the dorsal skin of mice was challenged with $150 \mu \mathrm{l}$ of $1 \% \mathrm{PiCl}$ dissolved in olive oil. After the first challenge, $1 \% \mathrm{PiCl}$ solution was repeatedly applied to the dorsal skin of mice for further 8 times at 1-week intervals. ${ }^{24,25)}$

Preparation of SC Extract The leaves of Saururus chinensis (Lour.) BAILl (Saururacae) as a dried herb was purchased from Omniherb (Youngchun, South Korea). It has grown in Andong of South Korea. Saururus chinensis was authenticated by $\mathrm{H}$. Bae, College of Oriental Medicine, Kyung Hee University. A voucher specimen was deposited at the Herbarium of the College of Oriental Medicine, Kyung Hee University. SC (600 g) was steeped in boiling distilled water for $30 \mathrm{~min}$ and filtered through a nylon mesh. After centrifugation at $5000 \mathrm{~g}$ for $20 \mathrm{~min} 4{ }^{\circ} \mathrm{C}$, the supernatant was freeze-dried, providing SC extract ( $90 \mathrm{~g}, 15 \% \mathrm{w} / \mathrm{w})$.

Quantitative Analysis of Rutin in SC SC extract was accurately weighed to $15 \mathrm{mg}$ and dissolved in $1 \mathrm{ml}$ of $50 \%$ methanol. For the quantitative analysis to $\mathrm{SC}$, rutin, one of the known flavonoid constituents of SC, was purchased from Sigma-Aldrich, Inc., U.S.A., as the standard material. Rutin was weighed to $1 \mathrm{mg}$ and dissolved in $1 \mathrm{ml}$ of $50 \%$ acetonitrile in methanol. The dissolved standard solution was diluted to $0.1,0.25$, and $0.5 \mathrm{mg} / \mathrm{ml}$, respectively. HPLC analysis was performed to authenticate SC. HPLC analysis were conducted using Waters system (Waters Co., Milford, MA, U.S.A.) with a $717+$ autosampler, 2487 dual $\lambda$ absorbance detector, and 1525 binary HPLC pump, and Waters Millennium $^{32}$ System (Waters Co., Milford, MA, U.S.A.) was used for data acquisition and integration. The samples were analyzed by reverse phase $\left(\mathrm{C}_{18}\right)$ analysis HPLC (XTerra ${ }^{\mathrm{TM}}$ $\mathrm{RP}_{18}, 4.6 \times 250 \mathrm{~mm}$ i.d., $5 \mu \mathrm{m}$, flow rate: $1 \mathrm{ml} / \mathrm{min}$, UV detection: $250 \mathrm{~nm}$ ) using a gradient solvent system of acetonitrile-methanol-water $(1: 1: 2 \rightarrow 1: 1: 0,30 \mathrm{~min})$. The relationship between the concentration and the peak-area was measured by the minimum square method ( $R^{2}$ value). The standard calibration curve for rutin is $Y=30146120 X+$ $282562.5\left(R^{2}=0.999\right)$. The average content of rutin in SC extract was calculated $54.6 \pm 1.2 \mathrm{mg} / \mathrm{g}(n=3)$ by the above formula (Fig. 1).

Administration of SC SC extract of different concentration $(100,250 \mathrm{mg} / \mathrm{kg}, 0.2 \mathrm{cc} / \mathrm{d})$ was orally administered by gastric intubation with an animal-feeding needle, $5 \mathrm{~d}$ per week for 8 weeks starting from 1 week after sensitization with $5 \% \mathrm{PiCl}$. $0.9 \%$ normal saline $(0.2 \mathrm{cc} / \mathrm{d})$ was orally administered as a control.

Evaluation of Skin Severity The severity of dermatitis was assessed macroscopically in a blinded fashion according to the following scoring procedure on the 63rd day after sensitization. The total scores of the skin severity are defined as the sum of the individual score grades from score 0 (no symptoms), score 1 (mild), score 2 (moderate), and score 3 (severe) for each of the following 4 signs and symptoms, erythema (hemorrhage), edema, excoriation (erosion), and dryness (scaling). ${ }^{25-27)}$

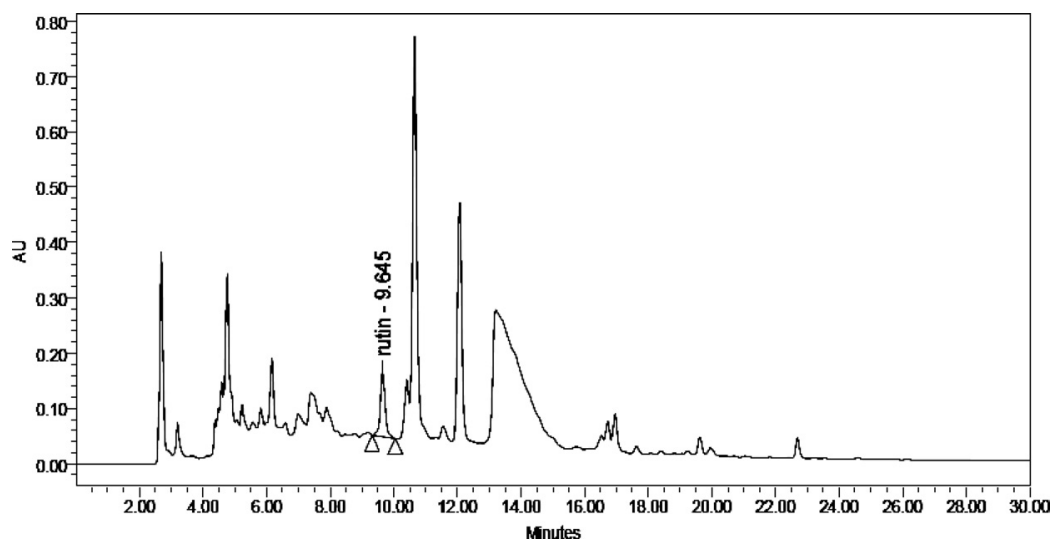

Fig. 1. HPLC Chromatogram of Leaf in Saururus chinensis

$\mathrm{XTerra}^{\mathrm{TM}} \mathrm{RP}_{18}, 4.6 \times 250 \mathrm{~mm}$ i.d., $5 \mu \mathrm{m}$, flow rate: $1 \mathrm{ml} / \mathrm{min}$, UV detection: $250 \mathrm{~nm}$, injection volume: $25 \mu 1$. 
Histological Study Mice were sacrificed on the 63rd day after sensitization. The auricular skin was removed, fixed in $10 \%$ formalin, embedded into paraffin, cut in $10-\mu \mathrm{m}$ sections, stained with hematoxylin-eosin solution. ${ }^{25)}$

Measurement of Itching Behavior The mouse was individually put into a clear plastic cage and the behaviors were videotaped for $30 \mathrm{~min}$ on the 63rd day after sensitization. The playback served for the observation of scratching of rostral back and biting of caudal back; a series of scratching and biting behaviors were counted as one bout of event. ${ }^{28)}$ The first $10 \mathrm{~min}$ was excepted from measurement as the adaptation period, the itching for the latter $20 \mathrm{~min}$ was counted as itching behavior.

Measurement of Serum IgE Level Blood was collected from the retro-orbital plexus of $\mathrm{NC} / \mathrm{Nga}$ mice while under ether anaethesia on the 63rd day after sensitization. Serum samples were obtained by centrifugation and stored at $-80^{\circ} \mathrm{C}$ until assay. ${ }^{25)}$ Serum IgE level was measured by a sandwich murine IgE ELISA kit (R\&D system Inc., U.S.A.). The OD (optical density) was determined by using a microplate reader.

Detection of IFN- $\boldsymbol{\gamma}$ and IL-4 Levels in Lymph Nodes Lymph nodes were collected from the whole body of NC/Nga mice while under ether anaethesia on the 63rd day after sensitization. Excised lymph nodes were homogenized in Isogen using HG 30 Homogenizer. One milliliter of homogenate was mixed with $200 \mu \mathrm{l}$ of chloroform vigorously, and centrifuged at $13000 \mathrm{rpm}$ for $15 \mathrm{~min}$ at $4{ }^{\circ} \mathrm{C}$ using a microcentrifuge. The aqueous phase was separated and RNA in the phase was precipitated by mixing $0.5 \mathrm{ml}$ of 2-propanol. The precipitate was washed with $75 \%$ ethanol and dried, and then dissolved in diethyl pyrocarbonate (DEPC)-treated water. The total RNA content was calculated based on the absorbance at $260 \mathrm{~nm}$ and the quality was confirmed by electrophoresis.

Reverse transcriptase-polymerase chain reaction (RT-PCR, Bioneer, Korea) was employed for the detection of mRNA. The primer sequence from $5^{\prime}$ to $3^{\prime}$ for $\beta$-Actin was, forward primer, GTG GGC CGC TAG GCA CCA, and reverse primer, CGG TTG GCC TTA GGG TTC AGG GGG G. The primer sequence from $5^{\prime}$ to $3^{\prime}$ for IFN- $\gamma$ was forward primer, TAC TGC CAC GGC ACA GTC ATT GAA, and reverse primer, GCA GCG ACT CCT TTT CCG CTT CCT. The primer sequence from $5^{\prime}$ to $3^{\prime}$ for IL-4 was, forward primer, ACG GAG ATG GAT GTG CCA AAC GTC, and reverse primer, CGA GTA ATC CAT TTG CAT GAT GC. A mixture of $11 \mu \mathrm{l}$ containing $1 \mu \mathrm{g}$ RNA, DEPC-treated water and random primer was heated at $70{ }^{\circ} \mathrm{C}$ for $10 \mathrm{~min}$ and then mixed with $4 \mu \mathrm{l}$ of $5 \times$ First Strand Buffer, $1 \mu \mathrm{l}$ of $10 \mathrm{~mm}$ deoxynucleoside triphosphate (dNTP) and $2 \mu \mathrm{l}$ of $0.1 \mathrm{M}$ dithiothreitol. After $5 \mathrm{~min}$ at $25^{\circ} \mathrm{C}, 1 \mu \mathrm{l}$ of reverse transcriptase (Superscript II) was added and RT, at $25^{\circ} \mathrm{C}$ for $10 \mathrm{~min}, 42^{\circ} \mathrm{C}$ for $50 \mathrm{~min}$ and then $70^{\circ} \mathrm{C}$ for $15 \mathrm{~min}$, was performed on TrioThermoblock. Then, cDNA at a volume of $1 \mu \mathrm{l}$ was mixed with $100 \mathrm{~mm}$ Tris- $\mathrm{HCl}(\mathrm{pH} 8.3), 500 \mathrm{~mm} \mathrm{KCl}, 1.5 \mathrm{~mm}$ $\mathrm{MgCl}_{2}, 0.01 \%$ gelatin, $10 \mathrm{~mm}$ dNTP, $5 \mathrm{U} / \mathrm{ml}$ ampliTaqDNA polymerase and $1 \mu \mathrm{M}$ primers (Stratagene) and PCR (denaturation at $94{ }^{\circ} \mathrm{C}$ for $1.5 \mathrm{~min}$, annealing at $62{ }^{\circ} \mathrm{C}$ for $1.5 \mathrm{~min}$ and extension at $72^{\circ} \mathrm{C}$ for $1.5 \mathrm{~min}, 35$ cycles) was performed on Trio-Thermoblock. Products were electrophoresed on $2 \%$ agarose gel containing ethidium bromide. The bands were recorded by Polaroid camera. Results were normalized by $\beta$ actin expression. ${ }^{29)}$

Data Analysis Experimental values were expressed as mean \pm S.E.M. (standard error of the mean). The statistical analysis of the results was done by One-way ANOVA and post hoc by Tukey's test. In all cases, $p<0.05$ was considered significant.

\section{RESULTS}

Comparison of Skin Severity The NC/Nga mice have been shown to develop AD-like skin lesions by repeated application of $\mathrm{PiCl}^{24-26)}$ In accordance with this previous finding, the clinical skin severity in control group increased gradually depending on the times of challenge with $\mathrm{PiCl}$ and reached a maximum on the 63rd day after the sensitization. All of the mice in control group exhibited AD-like skin lesions including eczema, erythema, excoriation and hemorrhage in the face, dryness, scaling and alopecia in the neck and dorsal skin (Fig. 2A). But, oral administration of SC suppressed the development of AD-like skin lesions (Figs. 2B, C).

The skin severity scores in SC100 group and SC250 group were significantly lowered compared to control group $(p<0.001)$ (Fig. 3). Although there was no significant difference in the clinical skin severity scores between SC100 group and SC250 group, the efficacy of SC $250 \mathrm{mg} / \mathrm{kg}$ administration was better than that of SC $100 \mathrm{mg} / \mathrm{kg}$ administration.

Histological Analysis Histological examination in control group showed surface hemorrhage, hypertrophy and hyperkeratosis of the epidermis. And intercellular edema, liquefaction degeneration of the basal layer was also observed in the epidermis. The infiltration of inflammatory cells including many lymphocytes, mast cells, neutrophils, eosinophils were found into the dermis and the epidermis (Fig. 4A). These inflammatory changes were not found in SC administered group (Fig. 4B).

Comparison of Itching Behavior The total counts of itching behavior for $20 \mathrm{~min}$ were decreased significantly in SC administered groups compared to control group $(p<0.001)$. The itching behavior in $\mathrm{SC} 250$ group was significantly lowered than that in SC100 group $(p<0.001)$ (Fig. 5).

Comparison of Serum IgE Level Serum IgE level was decreased in SC administered groups compared to control group, although there was no significant difference between serum IgE level of SC100 group and that of control group. Serum IgE level in SC250 group decreased significantly compared to control group $(p<0.001)$ and $\mathrm{SC100}$ group $(p<0.05)$ (Fig. 6).

Comparison of IFN- $\boldsymbol{\gamma}$ and IL-4 in Lymph Nodes IFN$\gamma$ mRNA expression in lymph nodes was detected very slightly in control group. IFN- $\gamma$ mRNA expression in SC100 group increased compared to control group. IFN- $\gamma$ mRNA expression in SC250 group increased compared to SC100 group (Fig. 7B). IL-4 mRNA expression in lymph nodes didn't show significant difference between SC administered groups and control group (Fig. 7C). 
A

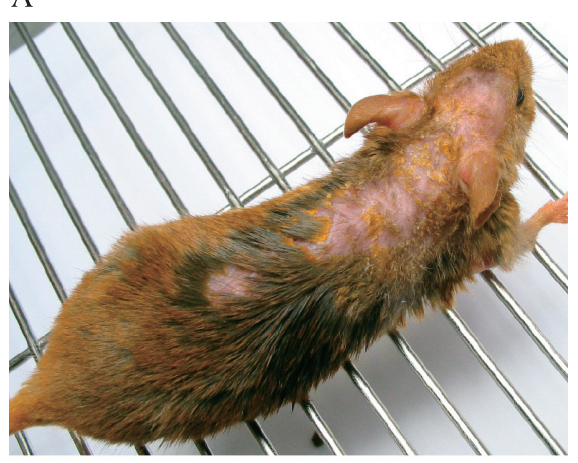

B

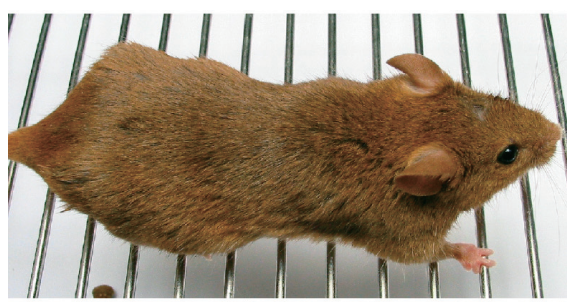

$\mathrm{C}$

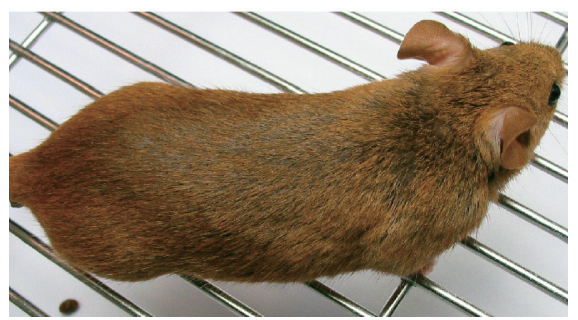

Fig. 2. Comparison of AD-Like Skin Lesions in NC/Nga Mice after Administration of Normal Saline and SC

The photographs were taken on the 63rd day after sensitization. (A) Control group $(0.9 \%$ normal saline administered, $n=7)$, (B) $\mathrm{SC} 100$ group $(100 \mathrm{mg} / \mathrm{kg}$ SC extract administered, $n=8)$, (C) SC250 group ( $250 \mathrm{mg} / \mathrm{kg} \mathrm{SC}$ extract administered, $n=8)$.

A

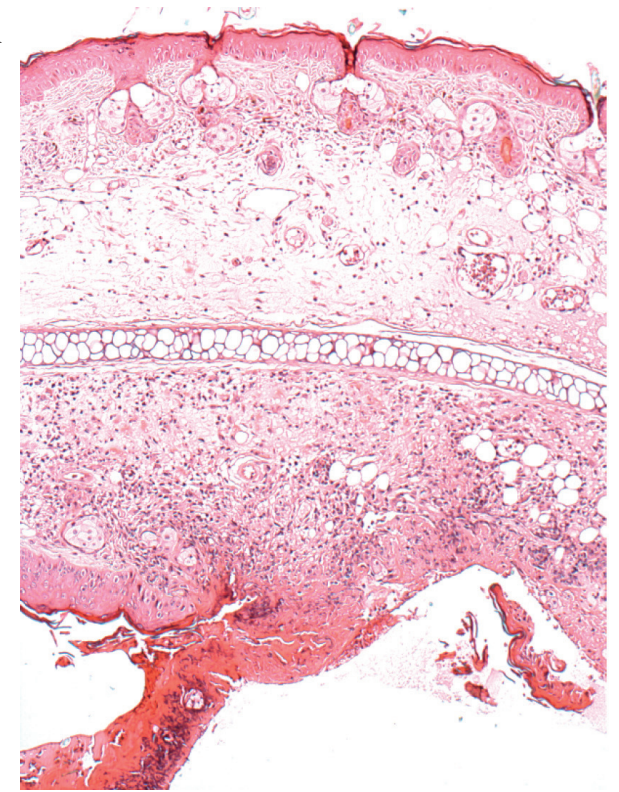

\section{DISCUSSION}

$\mathrm{AD}$ is a chronic eczematous skin disease accompanied by severe itching. ${ }^{30,31)}$ We previously reported that oral administration of Rumex japonicus HoutT (RJH), a herb used in Eastern countries for the management of cutaneous diseases including $\mathrm{AD}$, inhibits the development of $\mathrm{AD}$-like symptoms in NC/Nga mice with no apparent side-effects, by suppressing the Th2 cell response. ${ }^{32)}$

$\mathrm{SC}$ is also an herb used for the management of various skin diseases including AD in Eastern countries. SC contains flavonoids, including quercetin, quercitrin, isoquercitrin and rutin, as pharmacologically active components. Recently, it was reported that the flavonoids addressed above could suppress inflammatory reactions in vivo. The anti-inflammatory effect of these flavonoids suggests the possibility of their therapeutic efficacy in various inflammatory diseases. ${ }^{20)}$

In the present study, we investigated the inhibitory effects of $\mathrm{SC}$ on the development of $\mathrm{AD}$-like skin lesions in $\mathrm{NC} / \mathrm{Nga}$

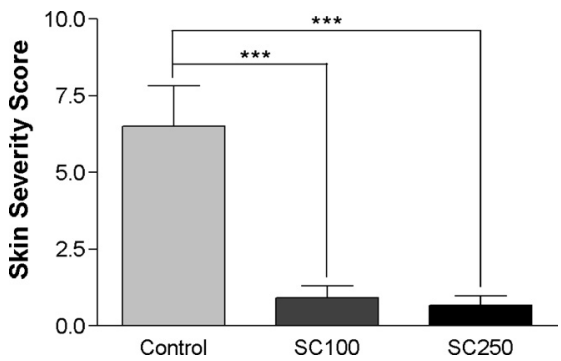

Fig. 3. Comparison of Skin Severity Score

The severity of dermatitis was assessed macroscopically in a blinded fashion according to the following scoring procedure on the 63rd day after sensitization. The total scores of the skin severity were defined as the sum of the individual score grades from score 0 (no symptoms), score 1 (mild), score 2 (moderate), and score 3 (severe) for each of the following 4 signs and symptoms, erythema (hemorrhage), edema, excoriation (erosion), and dryness (scaling). Values represent the means \pm S.E.M. of each group. $* * * p<0.001$ when compare SC100 group $(n=8)$ or SC250 group $(n=8)$ with control group $(n=7)$.

B

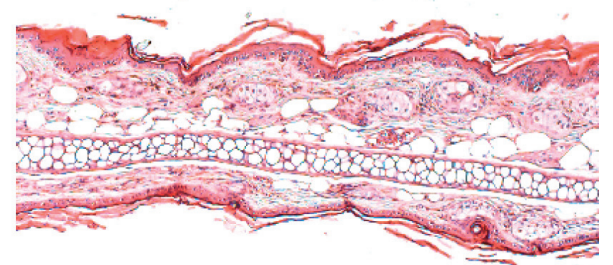

Fig. 4. Histological Comparison of SC Administered Groups and Control Group

The auricular skins from (A) control group and (B) SC administered groups were stained with hematoxylin-eosin. (A) Surface hemorrhage, hypertrophy, intercellular edema, liquefaction degeneration of the basal layer in the epidermis and the infiltration of inflammatory cells in the dermis were observed (100 $\times)$. (B) The inflammatory changes were not found in SC administered group $(100 \times)$. 


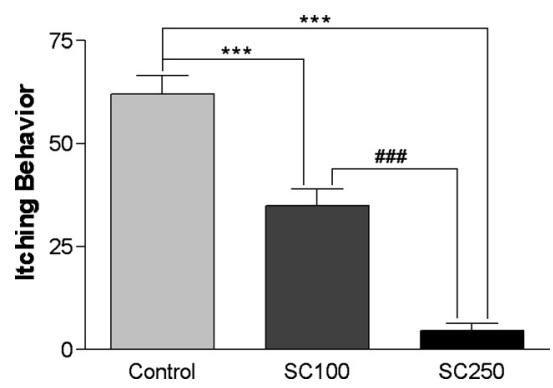

Fig. 5. Comparison of Itching Behavior

Itching behavior was measured as the number of scratching of rostral back and biting of caudal back for $20 \mathrm{~min}$ on the 63rd day after sensitization. $* * * p<0.001$ when compare SC100 group $(n=8)$ or SC250 group $(n=8)$ with control group $(n=7)$, \# $p<0.001$ when compare SC250 group with SC100 group.

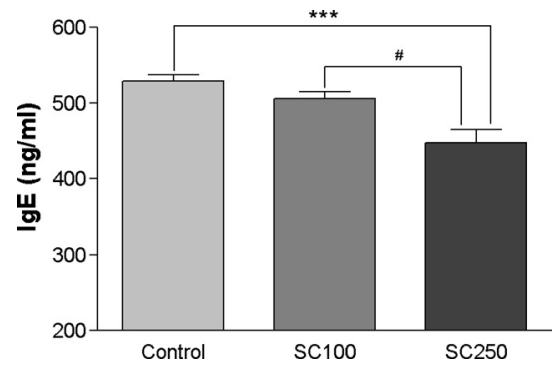

Fig. 6. Comparison of Total IgE in the Serum

Serum IgE concentration was measured to examine the effect of SC administration on systemic change by ELISA. Serum IgE level in SC250 group decreased significantly compared to control group and $\mathrm{SC} 100$ group. $* * * p<0.001$ when compare $\mathrm{SC} 100$ group $(n=8)$ or SC250 group $(n=8)$ with control group $(n=7)$, $\# p<0.05$ when compare SC250 group with SC100 group.

mice. NC/Nga mice are useful as an animal model for human AD. Skin lesions with increased numbers of eosinophils, mast cells, CD4+ T cells, and macrophages, which were clinically and histologically very similar to human AD, spontaneously developed in NC/Nga mice with a marked elevation in plasma levels of total IgE when raised in air-uncontrolled specific pathogen-free conditions. ${ }^{33)}$ In this study we used $\mathrm{PiCl}$ induced $\mathrm{AD}$-like skin lesions in $\mathrm{NC} / \mathrm{Nga}$ mice because $\mathrm{AD}$ induced by repeated application of $\mathrm{PiCl}$ in $\mathrm{NC} / \mathrm{Nga}$ mice is more valuable in its high reproducibility than spontaneous AD in NC/Nga mice. ${ }^{22)}$

There was a significant difference in the skin severity between SC administered groups and the control group. All of the mice in the control group exhibited AD-like skin lesions characterized by erythema, hemorrhage, excoriation, scaling, alopecia and dryness, whereas SC administered groups showed little change in the skin macroscopically (Fig. 2). In addition, the total skin severity scores were significantly reduced in SC administered groups (Fig. 3). Histologically, the control group showed hypertrophy, hyperkeratosis, intercellular edema, the liquefaction degeneration of the basal layer and infiltration of inflammatory cells in the skin, whereas SC administered groups showed a decrease in these changes (Fig. 4).

The itching behavior decreased significantly in SC administered groups compared to the control group (Fig. 5). Itching is one of the major diagnostic criteria of $A D,{ }^{34,35)}$ because the itching is the most important problem for atopic patients and scratching worsens the dermatitis itself. ${ }^{29)}$ Scratching their skin with toenails seemed to be the most important factor leading to dermatitis through increasing various immunologi-
A

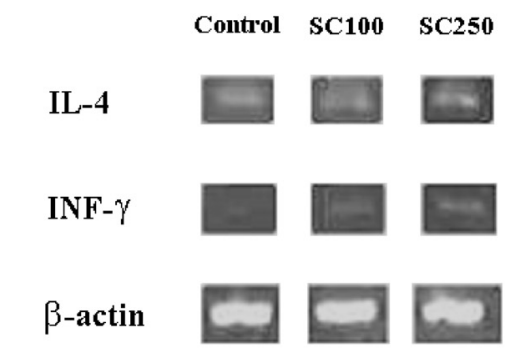

$\mathrm{B}$

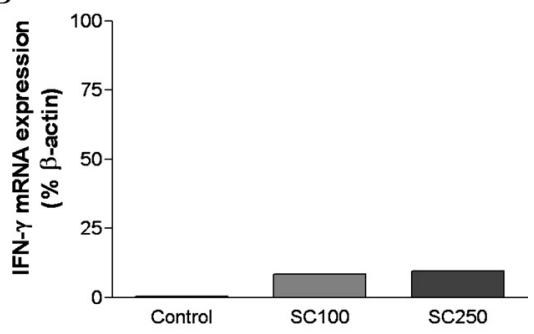

$\mathrm{C}$

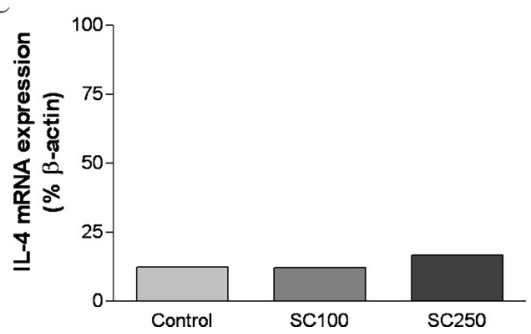

Fig. 7. Comparison of IFN- $\gamma$ and IL-4 in Lymph Nodes

IFN- $\gamma$ and IL- 4 mRNA expression in lymph nodes were measured to examine the effect of SC administration on cytokines by RT-PCR. Resultant electrophoretic bands (A) were semi-quantitatively evaluated using NIH Image software. Experiments were repeated at least twice and a representative experiment is indicated. Results are expressed as a ratio of (B) IFN- $\gamma$ and (C) IL-4 to $\beta$-actin mRNA expression.

cal responses such as the elevation of serum IgE concentration and the number of mast cells. ${ }^{36,37)}$ Therefore, SC may play an important role in controlling the pathology of AD because it significantly suppressed the itching behavior.

In this study, the serum IgE in SC administered groups was significantly lower compared to the control group. Many studies reported that the normal value of serum $\operatorname{IgE}$ of $\mathrm{NC} / \mathrm{Nga}$ mice in SPF condition remained under maximum $500 \mathrm{ng} / \mathrm{ml}$, usually under $250 \mathrm{ng} / \mathrm{ml}$, and the serum IgE level increased in NC/Nga mice with AD-like skin lesions. ${ }^{21,29,38)}$ In NC/Nga mice, the constitutive and enhanced Jak3 phosphorylation in B cells was attributed to the high-sensitivity of CD40L and IL-4 signaling. ${ }^{39)}$ In general, IgE synthesis by B cells is primarily regulated by cytokines. Th2 cytokines like IL-13, IL-4 play a key role for the hyperproduction of IgE, while Th1 cytokines, especially IFN- $\gamma$, are strong inhibitors of IgE synthesis, proliferation of Th2 cells, and expression of IL-4 receptors on T cells. It is well established that the elevation of serum IgE in AD may be due to the Th1/Th2 imbalance skewed to Th2, which plays important roles in the pathology of AD. Previous studies from other researchers reported that natural substances from plants or herbal therapy could inhibit the development of AD-like skin lesions in NC/Nga mice by modulating Th1 and/or Th2 cell response. ${ }^{29,38)}$ Thus, we measured the levels of IFN- $\gamma$ and IL-4 after SC treatment. Oral administration of SC enhanced IFN- 
Table 1. Body Weight Change

\begin{tabular}{lcccc}
\hline \hline & & Control & SC100 & SC250 \\
\hline Body weight $(\mathrm{g})$ & 1st day & $25.9 \pm 0.4$ & $25.4 \pm 0.6$ & $25.1 \pm 0.6$ \\
& Last day & $34.0 \pm 0.8$ & $31.6 \pm 1.0$ & $32.6 \pm 0.9$ \\
\hline
\end{tabular}

All groups were homogeneous in body weight in the beginning of experiment and the mean body weights on the day of sacrifice were not different between groups.

$\gamma$ production, but did not inhibit IL-4 production. These results imply that the SC treatment can reduce the serum levels of total IgE by promoting Th1 cell response, especially IFN$\gamma$. Because up-regulation of IFN- $\gamma$ did not lead down-regulation of IL-4, it could be considered that IFN- $\gamma$ might directly affect to B cells and inhibit IgE production. Anyway, we can conclude that SC exhibits the activity that modulates the Th1/Th2 imbalance skewed to Th2 in NC/Nga mice.

Although patients with AD may benefit from herbal therapy in Oriental medicine, the possibility of hepatic toxic effects or other side effects remains a concern. However, the weight gain in $\mathrm{NC} / \mathrm{Nga}$ mice during the experiment was not disturbed by $\mathrm{SC}$ extract administration (Table 1). In addition, the administration of SC extract appeared neither to cause tissue damage on macroscopic analysis nor to induce liver dysfunction (data not shown).

In conclusion, we demonstrated that the oral administration of SC inhibited the development of AD-like skin lesions in $\mathrm{NC} / \mathrm{Nga}$ mice. The results from the present study suggest that $\mathrm{SC}$ could inhibit the development of AD-like skin lesions in $\mathrm{NC} / \mathrm{Nga}$ mice, possibly through modulating the Th1/Th2 imbalance by the promotion of Th1 cell response. Since human is the genetically heterogeneous population, these results from the homogeneous inbred strain, $\mathrm{NC} / \mathrm{Nga}$, would be difficult to imply every human therapeutic usages. But the modulating activity of SC for the Th1/Th2 imbalance may play a role in their effectiveness for treating $\mathrm{AD}$, thus $\mathrm{SC}$ may be an alternative substance for the management of AD. Investigations to identify the major components of SC that are responsible for the inhibitory effects on $\mathrm{AD}$ are currently in progress.

Acknowledgements This work was supported by a grant from the MRC program (R13-2007-019-00000-0) of KOSEF, Republic of Korea. Three authors (S. K. Kim, H. J. An, and A.-R. Han) were supported by the Brain Korea 21 project in $2006-2007$.

\section{REFERENCES}

1) Williams H. C., Clin. Exp. Dermatol., 17, 385-391 (1992).

2) Abramovits W., Goldstein A. M., Stevenson L. C., Clin. Dermatol., 21, $383-391$ (2003).

3) van der Heijden F. L., Wierenga E. A., Bos J. D., Kapsenberg M. L., J. Invest. Dermatol., 97, 389-394 (1991).

4) van Reijsen F. C., Bruijnzeel-Koomen C. A., Kalthoff F. S., Maggi E., Romagnani S., Westland J. K., Mudde G. C., J. Allergy Clin. Immunol., 90, 184-193 (1992).
5) Gavett S. H., O'Hearn D. J., Li X., Huang S. K., Finkelman F. D., Wills-Karp M., J. Exp. Med., 182, 1527-1536 (1995).

6) Tang C., Inman M. D., van Rooijen N., Yang P., Shen H., Matsumoto K., O’Byrne P. M., J. Immunol., 166, 1471-1481 (2001).

7) Lack G., Bradley K. L., Hamelmann E., Renz H., Loader J., Leung D. Y., Larsen G., Gelfand E. W., J. Immunol., 157, 1432-1439 (1996).

8) Romagnani S., J. Allergy Clin. Immunol., 113, 395-400 (2004).

9) Mc Geady S. J., Pediatrics, 113, 1107-1113 (2004).

10) Abramovits W., J. Am. Acad. Dermatol., 53, S86-S93 (2005).

11) Koo J., Arain S., Arch. Dermatol., 134, 1388-1393 (1998).

12) Lee W. S., Baek Y. I., Kim J. R., Cho K. H., Sok D. E., Jeong T. S., Bioorg. Med. Chem. Lett., 14, 5623-5628 (2004).

13) Chung B. S., Shin M. G., "Dictionary of Korean Folk Medicine," Young Lim Sa, Seoul, Korea, 1990.

14) Sung S. H., Kwon S. H., Cho N. J., Kim Y. C., Phytother. Res., 11, 500-503 (1997).

15) Sung S. H., Kim Y. C., J. Nat. Prod., 63, 1019-1021 (2000).

16) Ahn B. T., Lee S., Lee S. B., Lee E. S., Kim J. G., Bok S. H., Jeong T. S., J. Nat. Prod., 64, 1562-1564 (2001).

17) Hwang B. Y., Lee J. H., Nam J. B., Hong Y. S., Lee J. J., Phytochemistry, 64, 765-771 (2003).

18) Scalbert A., Williamson G., J. Nutr., 130, 2073S-2085S (2000).

19) Parr A. J., Bolwell G. P., J. Sci. Food Agric., 80, 985-1012 (2000).

20) Morikawa K., Nonaka M., Narahara M., Torii I., Kawaguchi K., Yoshikawa T., Kumazawa Y., Morikawa S., Life Sci., 74, 709_721 (2003).

21) Matsuda H., Watanabe N., Geba G. P., Sperl J., Tsudzuki M., Hiroi J., Matsumoto M., Ushio H., Saito S., Askenase P. W., Ra C., Int. Immuno., 9, 461-466 (1997).

22) Shiohara T., Hayakawa J., Mizukawa Y., J. Dermatol. Sci., 36, $1-9$ (2004).

23) Kondo K., Nagami T., Teramoto S., "Comparative Cellular and Species Radiosensitivity,” ed. by Bondo P. V., Sugahara T., Igakushoin, Tokyo, 1969, pp. 20-29.

24) Okada M., Hirasawa Y., Yoshijima K., Imaeda T., Fujimura T., Nagase T., Kimura H., Kyuki K., Pharmacometrics, 59, 135-139 (2000).

25) Taniguchi Y., Kohno K., Inoue S., Koya-Miyata S., Okamoto I., Arai N., Iwaki K., Ikeda M., Kurimoto M., Int. Immunopharmacol., 3, $1313-1324$ (2003).

26) Ohmura T., Tsunenari I., Hayashi T., Int. Arch. Allergy Immunol., 133, 389-397 (2004).

27) Matsukura S., Aihara M., Hirasawa T., Ikezawa Z., Int. Arch. Allergy Immunol., 136, 173-180 (2005).

28) Maekawa T., Yamaguchi-Miyamoto T., Nojima H., Kuraishi Y., Jpn. J. Pharmacol., 90, 193-196 (2002).

29) Gao X. K., Fuseda K., Shibata T., Tanaka H., Inagaki N., Nagai H., eCAM, 2, 191-199 (2005).

30) Furue M., Furukawa F., Hide M., Takehara K., Jpn. J. Dermatol., 114, $135-142$ (2004).

31) Wahlgren C. F., Allergy, 47, 65-75 (1992).

32) Lee H. S., Kim S. K., Han J. B., Choi H. M., Park J. H., Kim E. C., Choi M. S., An H. J., Um J. Y., Kim H. M., Min B. I., Br. J. Dermatol., 155, 33-38 (2006).

33) Salob S. P., Atherton D. J., Pediatrics, 91, 8-15 (1993).

34) Koblenzer C. S., J. Allergy Clin. Immunol., 104, S109-S113 (1999).

35) Wahlgren C. F., J. Dermatol., 26, 770_779 (1999).

36) Hashimoto Y., Arai I., Nakanishi Y., Sakurai T., Nakamura A., Nakaike S., Life Sci., 76, 783 -794 (2004).

37) Mihara K., Kuratani K., Matsui T., Nakamura M., Yokota K., Br. J. Dermatol., 151, 335-345 (2004).

38) Kotani M., Matsumoto M., Fujita A., Higa S., Wang W., Suemura M., Kishimoto T., Tanaka T., J. Allergy Clin. Immunol., 106, 159-166 (2000).

39) Matsumoto M., Ra C., Kawamoto K., Sato H., Itakura A., Sawada J., Ushio H., Suto H., Mitsuishi K., Hikasa Y., Matsuda H., J. Immunol., 162, 1056-1063 (1999). 